\title{
Altered level of inflammatory markers in relation to glycemic status associated with adolescent diabetic patients
}

\begin{abstract}
The correlation between cytokine mediated acute phase inflammatory response and glycemic status of type 2 diabetic patients are almost fully established and well recognized but the correlation of inflammatory status with adolescent diabetic patients are still contradictory. In this present study we tried to establish the correlation of inflammatory condition with glycemic status in case of adolescent type 1 diabetic patients.

The plasma levels of $\alpha 1$ - antitrypsin, $\alpha 1$ - acid glycoprotein, ceruloplasmin and fibrinogen which used to consider as powerful inflammatory markers were determined for twelve newly diagnosed adolescent diabetic patients. We also took thirty normal controls matching with age and sex with the patients.

Although the results of various studies are widely variable and contradictory about the correlation of glycemic status with levels of acute markers that used to denote inflammatory conditions in case of adolescent diabetic patients but in our present study we can bit of predict that low graded inflammatory condition is definitely associated with glycemic status as well as pathogenicity of diabetes in adolescent age groups. For definitive diagnosis about the association between low grades inflammatory condition and development of type 1 diabetes mellitus obviously need further study and follow up.
\end{abstract}

Keywords: type 1 diabetes, chronic low grade inflammation, ceruloplasmin, fibrinogen
Volume 5 Issue 5 - 2018

\author{
Shamim Shaikh Mohiuddin \\ Department of Biochemistry, Imam Abdulrahman Bin Faisal \\ University, Saudi Arabia
}

Correspondence: Shamim Shaikh Mohiuddin, Department of Biochemistry, College of Medicine. Imam Abdulrahman Bin Faisal University, Saudi Arabia, Email smahiuddin@iau.edu.sa

Received: September 30, 2018 | Published: October II, 2018

\section{Introduction}

Diabetes mellitus is considered to be one of the most common public health disorders which have a wide range of distribution all over the globes. For development of adolescent diabetes mellitus, the major etiological factors are the synergistic effects of environmental, genetic and immunological factors which used to destruct the pancreatic $\beta$-cells mass. The main contributing factor for occurrence of type 1 diabetes in individuals of genetic susceptibility is due to process of autoimmunity that used to develop several months or even years which used to destroy the $\beta$-cells mass. ${ }^{1}$ Immunological markers are used to consider as main precipitating agent before diabetic condition is clinically overt. Although there was a well-maintained normal tolerance level of glucose but due drastically decline of mass of $\beta$ cells, insulin secretion is gradually decreasing. Clinical sign and symptom of diabetes mellitus usually caused when about $80 \%$ of $\beta$ cell mass used to destroy. At this point of time the number of residual functioning $\beta$ cells is insufficient to maintain the glucose tolerance. The triggering factor for transition from impaired glucose tolerance to frank diabetes are very frequently associated with requirement of more amount of insulin that may occur in infections or puberty. In human leukocyte antigen region (HLA region) on chromosome no 6 the major susceptibility gene of type 1 diabetes mellitus is located and this inheritance is mainly is of polygenic variety which used to account for $40 \%$ to $50 \%$ of genetic risk for developing of type 1 diabetes mellitus. Class II major histocompatibility complex (class II MHC) is encoded by genes which are situated in this region. The strongest association is with the DQ locus within this region and this locus is again further subtyped into $\alpha$ and $\beta$ loci. The haplotypes DQ A $1 * 0301$, DQ B1*0302, DQ A1*501 and DQ B1* 201 have the strongest association with type 1 diabetes that have shown after refinement in genotyping of HLA loci. It has been found that the amino acid in position 57 of the N-terminal $\beta-1$ domain of the HLA-DQ $\beta$ chain is directly related to susceptibility of type 1 diabetes although analysis of DNA sequence from patients with type 1 diabetes mellitus has not so far shown unique class II sequence. ${ }^{2}$ If individuals undergone infection or toxic insult, their immune system generally susceptible to develop a vigorous autoimmune process either against molecule of $\beta$ cell resembling the viral protein or against altered pancreatic $\beta$ cell antigens is felt to develop immune mediated type 1 diabetes mellitus. Although other types of islets cell are inexplicably spared from the autoimmune process though they are functionally and embryological similar to $\beta$ cells and expresses maximum of the similar proteins in $\beta$ cells. By the process called "Insulitis" the pancreatic islets are infiltrated with leucocytes. ${ }^{3}$

By some other cytokines like tumor necrosis factor $\alpha$ (TNF $\alpha$ ), interferon and interleukin 1(IL 1) $\beta$ cells are seen to be susceptible because of formation of nitric oxide metabolites, apoptosis and direct CD8+ T cell cytotoxicity which are responsible for death of $\beta$ cell. Islets gangliosides and carboxypeptidase $\mathrm{H}$ are other less clearly defined auto antigens. Question used to raise the process of destruction of $\beta$ cells because none of the auto antigens are $\beta$ cell specific except insulin. According to recent hypothesis an autoimmune process used 
to initiate by one $\beta$ cell molecules which then migrates to other islets molecules as the immune mechanism that demolished $\beta$ cells and form secondary auto antigens. $\beta$ cells of normal subjects do not differ the $\beta$ cells of individuals who develop type 1 diabetes mellitus since by a recurrence of the autoimmune process of type 1 diabetes mellitus transplanted islets are destroyed. ${ }^{4}$

A low grade inflammatory reaction is considered as an acute phase reaction which is associated with increase leukocyte count and temperature and is not specific for any given disease. A small protein known as Leucocytic Endogenous Mediator (LEM) which used to release from the injury site used to trigger all changes Plasma levels of the individual acute phase proteins rise at different rates. The levels of C-reactive protein and $\alpha-1$ antichymotrypsin rise first, and then level of $\alpha-1$ acid glycoprotein rises within 12 hours followed by the level of $\alpha-1$ antitrypsin, haptoglobin, C4 and fibrinogen and finally $\mathrm{C} 3$ and ceruloplasmin. Within 2-5 days, ${ }^{5}$ levels of all the parameters reach their maximum. Measurement of these proteins with the largest and earliest rises (eg CRP) can be used in monitoring the progress of inflammation or its response to treatment but these changes which are caused by increased synthesis in the liver don't aid in the diagnosis of the cause of inflammation. Decrease in the synthesis of prealbumin, albumin and transferrin are accompanied by increase in synthesis of ARP (so called negative acute phase reactants), so that in total only a slight rise plasma protein occurs. Therefore, nonspecific changes in level of individual proteins occur in inflammatory process which may mask changes attributable to a specific disease. ${ }^{6}$ the widely explored hypothesis in the notion that chronic low grade inflammation followed by activation of the innate immune system is closely involved in the pathogenesis of type 2 diabetes mellitus was first proposed in 199798. ${ }^{7}$ After that several studies have shown that circulating markers of inflammation, acute phase reactants or interleukin-6 ( IL-6) are strongly associated with the pathogenicity for development of type 2 diabetes but the role of acute phase reactants in case of type 1 diabetes mellitus is not very clear. ${ }^{8}$ Our present study is to detect the level of these inflammatory markers in the pathogenesis of type 1 Diabetes mellitus. Out of all inflammatory markers $\alpha 1$ - acid glycoprotein, $\alpha-1$ antitrypsin, fibrinogen and ceruloplasmin were of interest.

\section{Material and methods}

At first physicians examine the patient of previously undiagnosed diabetes in adolescent age groups and out of all confirmed cases, patients with a history of chronic inflammatory diseases, episodes of recent acute inflammations, patients with clinical evidence of neuropathy, nephropathy, and retinopathy were not enrolled in the study. Twelve Type 1 patient of either sex gave their consent to participate in the study. Thirty individuals of almost same age group were chosen to serve as controls. The control groups were applied the same exclusion criteria like of test groups. Institutional Ethics Committee approved the total test protocol. Body mass index (BMI) was calculated after recording of weight and height of each and every patients as well as controls. Random blood samples were collected before the initiation of therapy in the diabetic patients .Estimation of the following parameters were carried out:

i. Random plasma glucose (RBS): Detection of RBS by glucose oxidase method on Hitachi 917 autoanalyser using Roche Kits.

ii. Fibrinogen estimation: ${ }^{9}$ In presence of calcium chloride fibrinogen in plasma was converted to fibrin. The fibrin clot was collected and digested with sodium hydroxide. Protein content of the clot was determined by the biuret method. iii. Ceruloplasmin estimation: ${ }^{10}$ Paraphenylenediamine (PPD) is oxidized to yield a coloured product which is believed to correspond either to Bandrowski's base or to Weuster's red. This process is catalyzed by ceruloplasmin at $\mathrm{pH}$ 5.4. The rate of formation of the coloured oxidized product is proportional to the ceruloplasmin concentration, if a correction is made for the no enzymatic oxidation of PPD. Simultaneous estimations were carried out with and without sodium azide. Sodium azide inhibits the no enzymatic oxidation of PPD. The ceruloplasmin concentration is proportional to difference between the results of the two assays.

iv. $\alpha-1$ antitrypsin estimation: ${ }^{11}$ Casein used to hydrolyzed by proteolytic enzyme trypsin with the formation of smaller peptides. Tri-chloroacetic acid (TCA) arrested the enzymatic reaction after suitable interval of time with the precipitation of the proteins, but the peptides are soluble in the acid. The TCA soluble fragments are a measure of proteolytic activity of this enzyme. When the inhibitor is added to the preincubated mixture, it prevents the release of peptides by the proteolytic enzymes. Thus, the estimation of TCA soluble components in the presence and absence of inhibitor is a measure of inhibitory activity against proteolytic enzymes. The TCA soluble fragments were analyzed by the method of Lowry et al. ${ }^{12}$ The final color formed is a result of the reaction of the peptides with copper ions in alkali and reduction of the phosphomolybdic reagent by the presence of tyrosine and tryptophan present in the treated peptides.

v. Estimation of $\alpha-1$ acid glycoprotein: ${ }^{13}$ By application of perchloric acid heat coaguable proteins used to remove and the orosomucoid which remains in the solution was precipitated by phosphotungstic acid and estimated by determining its carbohydrate content by reaction with its tyrosine residues with folin ciocalteau reagent.

\section{Statistics and results}

With the application of the student's $t$ test and the ANOVA test the data was analyzed. For correlational analysis Pearson's coefficient was applied.

By the whole study our aim was to see whether low grade of chronic inflammation is a pathogenic cause in type 1 diabetes mellitus cases or not. In Table 1 the mean age (range), BMI and the number of males: females are presented. The control group participants were so chosen as to cover the age range of the test groups. Lists the values of random blood sugar (RBS) and acute phase proteins in both groups as mean \pm SD are denoted in Table 2. In comparison with the control group test group T- 1 had significant higher values of all the parameters which can be further supported by depicts the significance levels ( $p$ values) of the test and control groups which are denoted in Table 3.

Table I Characteristic of patients

\begin{tabular}{lll}
\hline & Controls $(\mathbf{n}=\mathbf{3 0})$ & Type I $(\mathbf{n}=\mathbf{I} \mathbf{2})$ \\
\hline Males: Females & $17: 13$ & $05: 07$ \\
Age & $43.97 \pm 14.06(30-60 \mathrm{yrs})$ & $47.27 \pm 7.11(30-60 \mathrm{yrs})$ \\
BMI & $20.75 \pm 2.27$ & $23.03 \pm 1.46$ \\
\hline
\end{tabular}


Table 2 Levels of the acute phase reactants as mean \pm SD

\begin{tabular}{|c|c|c|}
\hline Parameters & Controls mean \pm SD & $\begin{array}{l}\text { Type I } \\
\text { mean } \pm S D\end{array}$ \\
\hline Random blood Sugar (mg/dL) & $93.20 \pm 7.00$ & $338.25 \pm 50.97$ \\
\hline$\alpha$ I antitrypsin (mg/dL) & $349.48 \pm 114.07$ & $495.70 \pm 32.77$ \\
\hline$\alpha \mid$ acid glycoprotein(mg/dL) & $102.4 I \pm 22.13$ & $94.87 \pm 23.31$ \\
\hline Ceruloplasmin (mg/dL) & $25.95 \pm 4.10$ & $40.69 \pm 9.85$ \\
\hline Fibrinogen (mg/dL) & $334.34 \pm 42.19$ & $434.65 \pm 46.36$ \\
\hline
\end{tabular}

Table 3 Significance ( $p$ value)

\begin{tabular}{ll}
\hline Parameters & T-I v/s controls \\
\hline Random blood sugar $(\mathrm{mg} / \mathrm{dL})$ & $<0.000 \mathrm{I}^{*}$ \\
$\alpha$ I antitrypsin $(\mathrm{mg} / \mathrm{dL})$ & 0.0002 \\
$\alpha$ I acid glycoprotein $(\mathrm{mg} / \mathrm{dL})$ & 0.275 \\
Ceruloplasmin $(\mathrm{mg} / \mathrm{dL})$ & $<0.000 I^{*}$ \\
Fibrinogen $(\mathrm{mg} / \mathrm{dL})$ & $<0.000 I^{*}$
\end{tabular}

\section{Discussion}

By this entire study our aim was to determine whether there are any roles of inflammatory markers in pathogenesis of type 1 diabetes or not. Levels of $\alpha 1$-antitrypsin, ceruloplasmin and fibrinogen are significantly elevated in patients of type 1 diabetes mellitus in compare of control groups. According to previous studies regarding the level of acute phase reactant levels in Type 1 diabetes, various contradictory reports were found. Report by Gomes et al. ${ }^{14}$ denoted increased level of CRP, $\alpha 1$-acid glycoprotein and fibrinogen in Type 1 patients. John AD Elia et al. ${ }^{15}$ also shown increased fibrinogen levels, factor VII and whole blood viscosity. Defeo et al. ${ }^{16}$ almost found similar reports. In our present study, in case of type 1 adolescent patients an increased level of $\alpha 1$-antitrypsin, ceruloplasmin and fibrinogen were found. The course of the disease and resulting complications are almost similar in both type 1 and type 2 diabetic patients. Out of all the most fatal complication being that of development of atherosclerosis resulting in cardiovascular diseases. Out of our presently studied parameters fibrinogen is identified as an independent risk factor for the development of ischemic heart diseases. The risk of developing atherosclerosis remains the same irrespective of the patients being type 1 or type 2 . Hence there should have been some mechanism which links the pathogenicity of type 1 and type 2 diabetes. Barrazzani $\mathrm{R}$ et al. ${ }^{17}$ studied its role in fibrinogen production after infusion of insulin to non-diabetics as well as type 1 and type 2 diabetics. It was seen in non-diabetics and type 1 diabetic individual fibrinogen production suppressed due to insulin replacement activity. Despite the maintenance of euglycemia and euaminoaciduria fibrinogen production and its plasma concentration increased in case of insulin resistant type 2 diabetics. From these interesting phenomena they postulated that hyperfibrinogenemia in type 2 diabetic patients caused by an altered response to insulin. If this hypothesis is correct then it cannot analyses hyperfibrinogenemia in type 1 diabetics where the basic pathology is insulin deficiency.

Hence there should have some other stimulators which stimulate increased synthesis of fibrinogen in type 1 patients which leads to risk of cardiovascular disease. Based on clinical risk factor in patient with type 1 diabetes and validated using euglycemic-hyperinsulinemic clamp studies an insulin resistance syndrome scores. ${ }^{18}$ was developed and with this insulin resistance syndrome score fibrinogen levels were significantly associated. This may explain high level of plasma fibrinogen in type 1 diabetes by this phenomenon. But since the type subjects in this study were newly diagnosed, it still does not answer the above findings. The mechanisms by which fibrinogen increases cardiovascular risks are not fully understood. Fibrinogen plays important role in development of atherosclerosis starting from the stage of plaque formation till formation of occlusive thrombus over a ruptured atherosclerotic plaque, which is the most common precipitating cause of MI. ${ }^{19}$ The various mechanism by which fibrinogen has been found to promote atherosclerosis and thrombosis are hyperfibrinogenemia increases plasma viscosity, it induces reversible RBC aggregation, it binds It receptors on platelet membrane and causes platelet aggregation, it forms fibrin and fibrinogen degradation products (FDPs) which in turn bind LDL and sequester more fibrinogen and fibrinogen and FDPs stimulate smooth cell proliferation and migration..$^{20}$ Hence the mechanism of increased fibrinogen synthesis needs to be proved further and further specific studied needed. Ceruloplasmin is also an acute phase protein with a response of intermediate magnitude and is known to have antioxidant action. ${ }^{21}$ Ceruloplasmin used to Stimulate of cell proliferation and angiogenesis. ${ }^{22}$ for these higher levels of ceruloplasmin in contrast to control group, oxidative stress which used to prevalent in type 1 diabetes. ${ }^{23}$ may be played as prominent role. A very interesting feature of ceruloplasmin was showed by Eduardo E..$^{24}$ that in vitro intact human ceruloplasmin which is $132 \mathrm{KD}$ molecules caused increased oxidation of LDL. Starkebaum G and Harlan JM et al also showed excess oxidized LDL could be generated by increased serum ceruloplasmin and cause injury vascular bed by generating free radicals such as hydrogen peroxide. ${ }^{25}$ the antioxidant activity of ceruloplasmin was defined by these findings. By further investigations Eduardo Ehrenwald et al shown that the holoceruloplasmin has a prooxidant effect and the action was attributed to the copper ions present in ceruloplasmin. These holoceruloplasmin used to seen in serum as a $132 \mathrm{KD}$ molecule. The commercially available ceruloplasmin had an antioxidant effect and is a degraded product containing either $115 \mathrm{KD}$ fragment or 19KD fragment or both. As an antioxidant ceruloplasmin used these degraded products. The antioxidant action of a commercial ceruloplasmin was observed even in the system LDL. ${ }^{26}$ used to oxidize by holoceruloplasmin. Hence it is debatable whether ceruloplasmin acts as an antioxidant in vivo or not. The action of ceruloplasmin as an agent to oxidize LDL could probably explain at least in part of the increased risk of IHD in type 1 diabetes. (As well as in type 2 diabetics also).

It is still not very clear what are the underlying mechanisms for the augmented acute phase response and the stimulus for the response is unknown. Several hypotheses have been predicted and put forward and these include insulin resistance, obesity, atherosclerosis, other diabetic complications and maladaptation of the normal innate immune response to environmental threats. ${ }^{27-29}$ the association of obesity, insulin resistance, type 2 diabetes and acute phase reactants are few of all that are most widely studied. In the postprandial state. ${ }^{30,31}$ it has been shown that adipocytes secret several proinflammatory cytokines. In case of late for obese diabetics the term 'disability' has received attention. ${ }^{32}$ the 'common soil' theory proposed, evaluates the involvement of chronic low grade inflammation in the pathogenesis of atherosclerosis as well as in diabetes. This low grade chronic inflammation can be promoted by hyperglycemia and insulin resistance and inflammation may be a vital factor linking diabetes mellitus to the development of atherosclerosis. Promotion of these 
chronic low-grade inflammation by increasing oxidative stress, ${ }^{33}$ by the formation of AGEs and increased TNF (kappa B). ${ }^{34}$ is used to cause by elevated glucose level. In this present study, the mean BMI was found to be $19.5 \pm 1.23$ in type 1 patient and no proper correlation was found between acute phase reactants and BMI. That's why it can be concluded that there could be multiple pathways involved for activation of innate immune system and much work needed to be done to establish either a casual role in the development of type 1 diabetic patients in adolescent age groups.

\section{Conclusion}

For decades it's in our knowledge that of existence of two types of diabetes; the adolescent type 1 diabetes, where the main underlying defect is an absolute insulin deficiency due to an autoimmune destruction of the $\beta$ cells and the type 2 diabetes, where the basic defect is impaired secretion of insulin or an increased resistance to the action of insulin by the tissues which are sensitive to insulin. Then came the era of finding newer and more updated mechanisms involved in its pathogenesis. One of the recent mechanisms that received widely acceptance and paved way for further research is the role of activated innate immunity in the development of type 2 and probably type 1 diabetes. In continuation with the ongoing research world over we tried to examine whether this hypothesis holds true in case of newly developed adolescent type 1 diabetic patient. We can say with conviction that there is an activated innate immunity and a resultant increase in acute phase proteins in newly diagnosed type 1 diabetes. But due to small group of patients studied, we would say that the result should be interpreted with caution, although the inflammatory role and as a result augmented innate immune system cannot be ruled out

\section{Acknowledgements}

This work was done under guidance and advice by Dr Poornima Manjrekar, Department of Biochemistry, Kasturba Medical College, Mangalore, India.

\section{Conflict of interest}

The author declares that there is no conflict of interest.

\section{References}

1. Pugliese A. Unraveling the genetics of insulin dependent type I diabetes: The search must go on. Diabetes Rev. 1995;7:39.

2. Lowe WL. Genetics of diabetes. In: JL Jameson (ED). Principles of Molecular Medicine. 1998;433-442.

3. Schranz DB, Lernmack A. Immunology in diabetes, an update. Diabetes Metab Rev. 1998;14(1):3-29.

4. Christopher RW Edwards, Ian AD Boucher, Christopher H, et al. Endocrine and Metabolic Diseases; Diabetes Mellitus. In; Davidson's Principles and Practice of Medicine. ELBS, 17th Edition. 1995;725.

5. Murray RK, Granner DK, Mayers PA, et al. Plasma proteins, immunoglobulin and blood coagulation. In: Harper's Biochemistry. 25th Ed. Mc Graw Hill. 2002:740.

6. Tietz NW. Amino acids and proteins. In: Textbook of clinical chemistry: WB Saunders Company. Philadelphia. 1986;519-618.

7. Spranger J, Kroke A, Mohlig M, et al. Inflammatory cytokines and the risk to develop type 2 diabetes: results of the prospective population based European Prospective Investigation Cancer and Nutrition (EPICN)- Potsdam study. Diabetes. 2003;52(3):812-818.
8. Snijder MB, Dekker JM, Visser M, et al. C-reactive protein and diabetes type 2. Diabetologia.2001;115.

9. Varley H, Gowenlock AH, Bell M. Determination of plasma fibrinogen. In; Practical Clincial Biochemistry. 5th ed. CBS publishers and distributors; 1991;557-559.

10. Sunderman FW, Nomoto S. Measurement of human serum ceruloplasmin by its p-phenylenediamine oxi-dase activity. Clin Chem. 1970;16(11):903-909.

11. Sundaresh CS, Aroor AR, Pattabiraman TN. Compara-tive study of amidolytic and caseinolytic methods for the determination of urinary trypsin inhibitor. Indian J Med Res. 1978;68:341-347.

12. Loway OH, Rosebaugh NJ, Farr AL, et al. Pro-tein measurement with folin phenol reagent. J Biol Chem. 1951;193(1):265-275.

13. Winzler RJ. Determination of serum $\alpha-1$ acid gly-coprotein. In; Methods in Biochemical Analysis. Inter-science Pub. New York; 1955;2:270.

14. Gomes MB, Piccirilo LJ, Nogueira VG, et al. Acute phase proteins among patients with type1 diabetes. Diabetes Metab. 2003;29(4):405-411.

15. Elia JAD, Weinrauch LA, Gleason RE, et al. Fibrinogen and factor VII levels improve with glycemic control in patients with type 1 diabetes mellitus who have microvascular complication. Arch Int Med. 2001;161(1):98-101.

16. Defeo P, Volpi E, Lucidi P, et al. Physiological increments in plasma insulin concentration have selective and different effects on synthesis of hepatic proteins in normal humans. Diabetes. 1993;42(7):995-1002.

17. Barrazzani R, Kiwanuka E, Zanneti M, Cristini M: Insulin acutely increases fibrinogen production in individuals with type 2 diabetes but not in individuals without diabetes. Diabetes. 2003;52(7):1851-1856.

18. Williams KV, Erbey JR, Becker D, Arslanian S, Ochad TJ. Can clinical factors estimate insulin resistance in Type 1 diabetes. Diabetes. 2000;49:626-632.

19. Bembde AS. A study of plasma fibrinogen level intype-2 diabetes mellitus and its relation to glycemic control. Indian J Hematol Blood Transfus. 2012;28(2):105-108.

20. Brownlee M, Ulassara H, Cerami A. Nonenzymatic glycosylation reduces the susceptibility of fibrin to degradation by plasmin. Diabetes. 1983;32(3):680-684.

21. Allessandri G, Raju K, Gullino PM. Mobilization of capillary endothelium in vitro induced by effectors of angiogenesis in vivo. Cancer Res. 1983;43(4):1790-1797.

22. Telci A, Cakatay U, Salman S, Satman I, Sivus A. Oxidative protein damage in early stage type 1 diabetic patients. Diabetes Res clin Prac. 2000;50(3):212-223.

23. Baynes JW. Role of oxidative stress in development of complications of diabetes. Diabetes. 1991;40(4):405-412.

24. Ehrenwald E, Chisoim GM, Fox PL. Intact human ceruloplasmin oxidatively modifies low density lipoprotein. $J$ Clin Invest. 1994;93(4):1493-150.

25. Starkebaum G, Harlan JM. Endothelial cell injury due to copper catalyzed hydrogen peroxide generation from Homocysteine. $J$ Clin Invest. 1986;71(4):1370-1376.

26. Pickup JC, Crooke MA. Is type 2 diabetes mellitus a disease of the innate immune system? Diabetologia. 1998;41(10):1241-1248.

27. Grimble R. Inflammatory status and insulin resistance. Curr Opin Cli Nutr Metab. 2002;5(5):551-559.

28. Pradhan AD, Ridkar PM. Do atherosclerosis and type 2 diabetes share a common inflammatory basis?. Eur Heart J. 2002;23(11):831-834. 
29. Mohammed Ali V, Goodrick S, Rawesh A, et al. Subcutaneous adipose tissue releases interleukin-6, but not tumor necrosis factor $\alpha$, in vivo. $J$ Clin Endocrinol Metab. 1997;82:4196-4200.

30. Hotamisligil GS, Amer P, Cam JF, et al. Increased adipose tissue expression of tumor necrosis factors $\alpha$ in human obesity and insulin resistance. J Clin Invest. 1998;90:2409-2415.

31. Fried SK, Budkin DA, Greenberg AS. Omental and subcutaneous adipose tissues of obese subjects release interleukin-6. adipose tissue difference and regulation by glucocorticoids. J Clin Endocrinol Metab. 1998;83(3):847-850.
32. Duncan BB, Schmidt MI, Pankow JS, et al. Low grade inflammation and development of type 2 diabetes. The Atherosclerosis Risk in Communities study. Diabetes. 2003;52(7):1799-1805.

33. Bayens JW, Thorpe S. Role of oxidative stress in diabetic complications. a new perspective on an old paradigm. Diabetes. 1999;48(1):1-9.

34. Brownlee M. Biochemistry and molecular cell biology of diabetic complication. Nature. 2001;414:813-820. 